\title{
Malnutrition or healthy senescence
}

\author{
W. Cameron Chumlea ${ }^{1 *}$, Bruno Vellas ${ }^{2}$ and Shumei S. Guo ${ }^{1}$ \\ ${ }^{I}$ Department of Community Health, Wright State University School of Medicine, Dayton, OH 45435, USA \\ ${ }^{2}$ Department de Medecine Geriatrique, CHU Purpan-Casselardit, University de Toulouse, Toulouse, France
}

There are undeniable changes in the body's composition with old age, and these changes can bring about a plethora of physiological consequences affecting levels of function, and current and subsequent health (Rosenberg, 1989; Heymsfield et al. 1995). Health and function are interrelated states within the ageing process (Nagi, 1976), and transitions amongst them and disease and disability are affected by alterations in the body's composition through the ageing process. The expression and uniformity of changes in body composition vary among healthy, sick and malnourished elderly men and women. This variation affects our interpretation of estimates, measures, indices, and changes in body composition as related to levels of health and function in the elderly. These relationships are further affected by the fact that the elderly of today are some of the first recipients of the improvements in health and nutrition that have occurred during the twentieth century. The present paper reviews some of the issues relating levels of and changes in body composition with health and function among today's elderly. If body composition changes in old age, from what levels are the changes occurring? What is the timing or age at onset of the changes and how appropriate are existing body composition reference data for elderly people today?

\section{Healthy senescence from adulthood into old age}

Within the continuum of adult life, a major characteristic of body composition in normal, healthy adults appears to be that of increasing fatness. Overlaid on this period, if not the entire lifespan, are the effects of a modern lifestyle with its low levels of physical activity and the questionable quality and health benefits of many current diets. Most adults experience a creeping increase in body weight and fatness, and the increased prevalence of adult obesity is clear (Kuczmarski et al. 1994). Total body fat increases, as does the percentage of body fat, in both men and women (Guo et al. 1997c). Thus, many adults will enter the onset of old age today with potentially high levels of adiposity. Some have argued that this fatness is beneficial for mortality (Andres, 1985), despite the associated cardiovascular health risks. Moderate overweight among the elderly is reported to be associated with lower mortality, implying that a limited increase in weight with old age is beneficial (Andres, 1985; Andres et al. 1993). However, this relationship with mortality is confounded by the loss of weight from middle to old age among those individuals with the highest weight levels who are experiencing poor health (Losonczy et al. 1995). The obese in middle age start to lose weight as a result of, or in conjunction with, the onset of chronic disease. At the same time, non-obese middle-aged to elderly individuals, including those who had remained weight stable even at a low level, tended to preserve their health (Losonczy et al. 1995).

Most of the early reports of the changes in body composition with increasing old age used trends or values calculated from cross-sectional studies (see Brozek, 1963; Forbes, 1987). These studies indicated that continuous decreases in amounts of water, muscle and bone occur in both men and women, and these trends started as early as the 5th or 6th decade of life. More recently, where healthy adults in the Fels Longitudinal Study have been followed up to 65 years of age, serial measures of amounts of total body water and fat-free mass (FFM) have, on average, remained relatively stable in the men (Chumlea et al. 1997b; Guo et al. 1997c). This pattern of stability is similar for women also, but only until about 50 years of age and/or the occurrence of menopause. After menopause in these healthy women, there are small decreases in total body water, FFM, and bone mineral content and density (Chumlea et al. 1997b; Guo et al. 1997c; Zeller et al. 1997).

Cross-sectional data from the New Mexico Aging Process Study (see Garry, 1997) indicate that healthy successfully-aged men and women 60-70 years of age, on average, tend to have larger amounts of bone, muscle and fat than similar groups of persons over 70 years of age (Table 1 ).

Table 1. Mean values for body composition variables in healthy elderly New Mexico Aging Process Study participants (see Garry, 1997)

\begin{tabular}{|c|c|c|c|c|}
\hline \multicolumn{2}{|c|}{ Age-group . . . } & \multirow{2}{*}{$\begin{array}{c}60-70 \text { years } \\
17 \\
58 \cdot 2^{\mathrm{a}} \\
23.4 \\
3.1\end{array}$} & \multirow{2}{*}{$\begin{array}{c}70-80 \text { years } \\
78 \\
55.4^{b} \\
20.0 \\
2.8\end{array}$} & \multirow{2}{*}{$\begin{array}{c}80+\text { years } \\
37 \\
53 \cdot 4^{\mathrm{c}} \\
21.8 \\
2.8\end{array}$} \\
\hline Men & $\begin{array}{l}n \\
\text { FFM }(\mathrm{kg}) \\
\text { TBF }(\mathrm{kg}) \\
\text { TBM }(\mathrm{kg})\end{array}$ & & & \\
\hline Women & $\begin{array}{l}n \\
\text { FFM (kg) } \\
\text { TBF (kg) } \\
\text { TBM }(\mathrm{kg})\end{array}$ & $\begin{array}{l}50 \\
40 \cdot 0^{a} \\
26 \cdot 5^{a} \\
2 \cdot 1^{a}\end{array}$ & $\begin{array}{l}80 \\
37 \cdot 7^{b} \\
24 \cdot 5^{b} \\
1.9^{b}\end{array}$ & $\begin{array}{l}51 \\
37 \cdot 3^{\circ} \\
21 \cdot 4^{c} \\
1 \cdot 8^{c}\end{array}$ \\
\hline
\end{tabular}

FFM, fat-free mass; TBF, total body fat; TBM, total body mass.

$a, b, c$ Mean values in rows with unlike superscript letters were significantly different $(P<0.05)$ 
There is approximately a 2-3 $\mathrm{kg}$ difference in FFM between the 60-70 years age-group and the 70-80 years age-group for both the men and women. Between the two older age-groups, the differences in average amounts of bone, muscle and fat are generally not as large as these initial changes, although FFM in the men and total body fat in the women continue to decline from 70-80 years of age and the age-group over 80 years of age (Table 1). The average body composition values for these healthy elderly men and women at 60 years of age (Table 1) are similar to corresponding values for persons followed serially in the Fels Longitudinal Study (Chumlea et al. $1997 b$; Guo et al. 1997c). After about 60 years of age, the average changes in body composition appear to occur earlier in the ageing process rather than later among the healthy elderly. These current serial and cross-sectional findings from adulthood into old age demonstrate that the accepted or expected loss or decline in body composition with old age is not a continuous process starting early in middle age, except for women. After about 70 years of age, the changes in body composition that have been occurring in healthy men and women appear to abate.

The changes in body composition that occur with old age in the healthy elderly start with menopause in women and appear to continue to about age 70 years. Similar, but less severe, changes appear in healthy men from about age 60-70 years. These changes are, in part, hormonally related in both women and men, but a male climacteric is difficult to determine. Some of the variance in levels of body composition among older adult men and women is due to different levels of physical activity and the onset of menopause in women (Guo et al. 1997c; Zeller et al. 1997). When significant declines in body composition do occur, early or late in the ageing process, this event may be an expression of individual variation, or it may be a risk factor for subsequent health and functional problems, possibly sooner rather than later in life. Significant changes in body composition in old age, or at any age, appear to herald the onset of, or the concurrence with, disease, poor health and functional disability (Garry, 1997).

\section{Sarcopenia and weight-related health conditions}

The amount of muscle mass in the body is an important predictor of the outcome in critical illness (Hill, 1992), and low body weight in old age may be an indicator of possible sarcopenia. Sarcopenia has been defined at a recent National Institute on Aging workshop (Lexell \& Dutta, 1997) as a loss of muscle function at the impairment level within the framework of the disablement process (Guo et al. 1997a). A loss of muscle mass can affect the outcome of chronic disease and increase the risk for functional limitation and disability, all of which can also affect the amount of muscle mass (Chumlea et al. 1997a; Dutta et al. 1997; Guo et al. 1997a; Schwartz, 1997). A loss of weight during old age is an important health indicator, but reliable valid assessments or indices of levels of FFM in the elderly are necessary to help screen for sarcopenia. However, the amount of muscle mass that delineates the degree and prevalence of sarcopenia has not been determined clearly, due to the limited quality of current reference data. In addition, understanding the relationship between declines in muscle mass and morbidity, function, disability and mortality is complicated by several factors; these include the accuracy and reliability of the methods of measuring body composition, and the effects of age, sex, race, genetic and behavioural factors. We should expect the levels or amounts of muscle mass that might distinguish sarcopenia to vary depending on the population in question, and as a function of age, sex, race and possibly cohort differences.

Weight-related health conditions, including sarcopenia and obesity, limit an individual's physical ability to move around freely, and their social interaction with friends and neighbours. Weight-related health conditions also include osteoarthritis, cardiovascular disease, vascular disease, diabetes and glucose intolerance. The prevalence of weightrelated conditions among the elderly is approximately $47 \%$ of community-based 65-year-old individuals (Seeman et al. 1989). With this prevalence, it is important to measure the presence and onset of weight-related health conditions so that co-morbid associations can be determined. The complex interactions resulting from co-morbidity should be considered, especially since the incidence of co-morbidity (excluding sarcopenia) in community-based elderly is $60 \%$ and has a major effect on individual health (Guralnik et al. 1989; Kaplan et al. 1992). The contribution of changes in body composition to this co-morbidity needs to be established, as well as its effect on the prevalence of all weight-related health conditions in the elderly.

\section{Body composition screening in the elderly}

A major difficulty in quantifying body composition among the elderly is the questionable validity of assumptions underlying measures and estimates of muscle, fat and bone during the ageing process, especially when confounded by disease and disability. For example, FFM can also be estimated from measures of total body water based on the assumption that approximately $73 \%$ of total body water resides in the FFM. However, the universality of this assumption in the elderly is suspect, because chronic disease can affect the retention or loss of body water or alter the proportions of extra- and intracellular water (Steen et al. 1985; Roubenoff \& Kehayias, 1991). Dual-energy X-ray absorptiometry is recommended for body composition analyses of the elderly (Haarbo et al. 1991; Johnson \& Dawson-Hughes, 1991; Laskey et al. 1991). This technique is now widely used, but has not been universally accepted because of methodological problems and systematic differences among manufacturers (Roubenoff et al. 1993; Kohrt, 1995; Guo et al. 1997b). Bioelectrical impedance, both single and multifrequency, remains a potentially useful method of measuring body composition in the elderly (Chumlea \& Guo, 1994). However, the validity of bioelectrical impedance has not been well established, except in small samples of the elderly with limited age-ranges (Deurenberg et al. 1990). Thus, there is no universally suitable method of measuring body composition in the elderly that is immune to problems of non-universal assumptions, limited by available methodology or affected by aspects of chronic disease and functional disability. Our knowledge of body composition and its changes with old age are further compromised when applied to women or members of non-white racial or ethnic groups of elderly individuals around the world. 
Anthropometric measurements primarily infer information about body size, amounts of skeletal muscle and fatness. These inferences are meaningful as long as the body's systems are homeostatic, but can change with disease and disability. Anthropometric measurements can be used to screen for levels of body composition in a variety of health, nutritional and functionally-related contexts to monitor or account for elderly individuals at risk. For example, calf circumference is a sensitive measure of the loss of muscle mass in the elderly, and is recommended by the World Health Organization (1995) as a measure of nutritional status in the elderly. Calf circumference is also used together with arm circumference as a validated nutritional screening instrument for malnutrition in the elderly (Guigoz et al. 1994). Low values of arm and calf circumference are related to greater degrees of malnutrition than BMI, and more so in the sick elderly (Chumlea et al. 1995).

\section{Body composition and function}

Muscle mass is the functional component of body composition, but its interaction with function is not always clearly delineated. Functional status is a measure of physiological mechanisms and of biological abilities (Katz et al. 1963), and functional health is a significant predictor of positive health outcomes in the elderly, as well as being a prognostic indicator of disability (Guralnik \& Kaplan, 1989). Objective tests of physical performance have improved measures of functional status (Guralnik et al. 1994). Performance-based assessments are related to measures of muscle strength, but not to levels of muscle mass (Cress et al. 1995). Strength, however, is directly determined by the amount of muscle mass (Pearson et al. 1985; Frontera et al. 1991), and changes in muscle strength are related to concurrent changes in muscle mass (Young et al. 1984). A decrease in strength with age may also be produced by alterations in the neurological and contractile properties of muscle tissue. The decrease in strength with age results from the atrophy of some fibres and the loss of others caused by degeneration of the number of neuromuscular junctions (Lexell et al. 1983; Balice-Gordon, 1997). All these changes are probably related to reduced levels of physical activity (Bassey, 1997). Thus, measures of strength should be considered as a possible screening tool for elderly subjects to assess their ability to live independently, and their risk for future health and functional problems. For example, measures of lower body strength are related to changes in muscle mass of the legs, and predict the occurrence of falls and problems with gait and balance (Shephard et al. 1991; Fiatarone et al. 1994; Wolfson et al. 1995). Strength of the quadriceps is a valid indicator of lower-body functional capacity and performance in elderly subjects. Also, dual-energy X-ray absorptiometry allows regional measures of muscle in the legs, and these measures could be correlated with levels of strength in the legs in the elderly.

\section{Reference values}

Among the available sets of reference data for the elderly, some are no longer representative of the sample of elderly persons living today. For example, Damon \& Stoudt (1963) published data for elderly men. These data were collected from Spanish-American War Veterans, many of whom were born in the $1870 \mathrm{~s}$, and all of whom are now dead. The report by Masters et al. (1960), has been recommended as 'the best data currently available' for the elderly (Ham, 1991); however, it includes individuals who were born between 1865 and 1895. Most of these individuals are now deceased also. The present living very old elderly were born between about 1900 and 1913. Because of the occurrence of what is called the secular trend among world populations during the twentieth century (Eveleth \& Tanner, 1976), it is very doubtful that data from persons born in the ninetieth century are relevant for elderly persons living on the eve of the twenty-first century.

Subsequent generations born during the twentieth century were significantly larger in stature and weight than previous generations and reached maturation earlier. This phenomenon was reported in the USA about 1932 (Blackfan, 1932), and eventually it occurred worldwide (Eveleth \& Tanner, 1976). The secular trend has now stopped in the USA (Roche, 1979) and in many other developed countries (Eveleth \& Tanner, 1976). The generation that fought in World War II was the first to be widely identified with this phenomenon (Blackfan, 1932), and this is the generation that comprises the majority of the elderly people alive today. The causes of this secular trend are reportedly numerous, but improved nutrition and public health are high on the list. Thus, the present generation of elderly is probably the first to have benefitted fully from the effects of improved nutrition and health during childhood, that helped to make them taller and heavier as adults than their parents (Stini, 1981). These beneficial effects (and improvements) have persisted as this generation has aged, and may be affecting the course of their ageing as compared with that of previous generations, especially in terms of the prevalence of healthy ageing. However, it is important to recognize that even among cohorts of elderly persons today, significant group and racial differences existed during their growth and maturation, health and living conditions, and levels of nutritional status as children and adults (Boyd, 1980). The results of these effects and initial differences among these groups may have increased in old age.

\section{Current reference data}

Mean values and distribution statistics for stature, weight and other selected body measures of the elderly are available from several national health surveys and large clinical studies in several different countries (Abraham et al. 1979; Najjar \& Rowland, 1987; DeGroot et al. 1991; Vellas et al. 1992; World Health Organization, 1995). For those 80 years of age and older, available reference data are scarce, even though proportionately this is the fastest growing segment of many world populations (Chumlea \& Baumgartner 1989; Czajka-Narins et al. 1991; World Health Organization, 1995). Suitable reference data for the present generations of elderly in the USA are available from the National Health and Nutrition Examination Survey (NHANES) III (Woteki et al. 1988). For elderly persons in Europe, a primary current source of data is the Survey in Europe on Nutrition and the Elderly, a Concerted Action (SENECA) study (DeGroot et al. 1991). The increase in the prevalence of obesity in the 
Table 2. Approximate samples for elderly data in National Health and Nutrition Examination Survey III by selected age-groups

\begin{tabular}{lccccc}
\hline & $60-69$ & $70-79$ & $80-85$ & $85-90$ & $90+$ \\
Age-group . . & years & years & years & years & years \\
\hline White men & 481 & 634 & 456 & 176 & 40 \\
White women & 474 & 564 & 426 & 210 & 48 \\
Black men & 266 & 224 & 32 & 20 & 8 \\
Black women & 296 & 202 & 76 & 28 & 6 \\
Mexican-American men & 312 & 160 & 50 & 16 & 0 \\
Mexican-American women & 294 & 134 & 36 & 14 & 6 \\
\hline
\end{tabular}

US adult population including the elderly (Kuczmarski et al. 1994), raises concerns about the use of NHANES III data as a health reference, especially for determining levels of low muscle mass or sarcopenia.

The data for the elderly in NHANES III (Woteki et al. 1988) consists of a sex-and racial or ethnic-stratified sample of approximately 4750 persons from the US population aged 60 years and older. This includes approximately 1369 Caucasian men 60-102 years, 1472 Caucasian women 60-98 years, 474 non-Hispanic Black men 60-97 years, 481 non-Hispanic Black women 60-92 years, 497 MexicanAmerican men 60-97 years and 457 Mexican-American women 60-97 years. These large numbers would appear to indicate an adequate sample size, but when the sample is broken down by 10- and 5-year age-groups (Table 2), it becomes clear that few persons are represented above 85 years of age for the non-Hispanic Whites and even fewer above 79 years for the non-Hispanic Blacks and MexicanAmericans. In addition, these data are not suitable for the calculation of percentiles for BMI, weight, etc. even after adjusting the data to be representative of the US population (Landis et al. 1982). The calculation of precise conventional percentiles for BMI from the 5 th to the 95 th levels requires 250-300 individuals within a 5-year age-group (S. Guo, unpublished results). Calculation of such percentiles for White women from 60 to 100 years of age would require a sample of 2700 , and the calculation of such percentiles for White women from 60 to 85 years of age would require a sample of 1800 . Calculation of precise percentiles from the 25 th to the 75th levels requires 100 individuals within each and every 5-year age-group, so that the calculation of such percentiles for White women from 60 to 100 years of age would require a sample of 900 . In terms of numbers of individuals, the NHANES III sample of elderly is limited to the determination of precise reference percentiles at the 25th and 75th levels from 60 to 90 years of age for non-Hispanic Whites, but only from 60 to 79 years of age for non-Hispanic Blacks and Mexican-Americans.

There are numerous small sets of data for elderly persons living in the USA and in other countries around the world. Many of these studies are well designed and have provided much important and valid information. Such data sets are frequently from samples of convenience and they are not representative of the general population of elderly. The utility or suitability of these data sets in describing levels of body composition for large segments of the elderly population and across national borders are limited, and should be approached with caution.

\section{Conclusion}

With the onset of old age, we are hampered in describing relationships between body composition and health and function by the limited availability of adequate serial data, and possibly by cohort and health effects among study groups reported over the past several decades. Much of our information on the changes in the body's composition with old age is from several important studies that are 30 years old. These reports, along with some limited survey data for body weight and anecdotal reports from small samples, provide the basis of much of our current understanding of the changes in body composition with old age. More recent data for body composition in the elderly is presenting a picture that is different from that reported for earlier generations or cohorts. No one would argue that changes in body composition with age are not real, but their individual expression and age of occurrence among elderly people today who are ageing successfully and subsequent generations have been affected by improved levels of lifelong health and nutrition. Obviously, there remains a distinct need for more national reference data for body composition measures that have larger samples and are suitable for describing differences between individuals, relationships with function, and levels of muscle mass related to malnutrition and the risk of sarcopenia.

\section{Acknowledgements}

This work was supported, in part, by grants HLDK-53404, HD-12252 and HD-27063 from the National Institutes of Health, Bethesda, MD, USA.

\section{References}

Abraham S, Johnson CL \& Najjar MF (1979) Weight and Height of Adults 18-74 Years of Age. Vital and Health Statistics, Series 11, no. 211. DHEW Publication no. (PHS) 79-1659. Rockville, MD: National Center for Health Statistics.

Andres R (1985) Mortality and obesity: The rationale for age-specific height-weight tables. In Principles of Geriatric Medicine, pp. 311-318 [R Andres, EL Bierman and WR Hazzard, editors]. New York, NY: McGraw-Hill.

Andres R, Muller DC \& Sorkin JD (1993) Long-term effects of change in body weight on all cause mortality. Annals of Internal Medicine 119, 737-743.

Balice-Gordon RJ (1997) Age-related changes in neuromuscular innervation. Muscle and Nerve Suppl. 5, S83-S87.

Bassey EJ (1997) Measurement of muscle strength and power. Muscle and Nerve Suppl. 5, S44-S46.

Blackfan KD (1932) Growth and Development of the Child. Part III, Nutrition. White House Conference on Child Health and Protection. New York, NY: The Century Co.

Boyd E (1980) Origins of the Study of Human Growth. Corvallis, OR: University of Oregon Health Sciences Foundation.

Brozek J (1963) Body composition part II. Annals of the New York Academy of Sciences 110, 425-1018.

Chumlea WC \& Guo S (1994) Bioelectrical impedance and body composition: Present status and future directions. Nutrition Reviews 52, 123-131.

Chumlea WC, Guo SS, Vellas BJ \& Guigoz Y (1995) Techniques of assessing muscle mass and function (sarcopenia) for epidemiological studies of the elderly. Journals of Gerontology 50A, 45-54. 
Chumlea WmC \& Baumgartner RN (1989) Status of anthropometry and body composition data in elderly subjects. American Journal of Clinical Nutrition 50, 1158-1166.

Chumlea WmC, Guo S, Glaser RM \& Vellas BJ (1997a) Sarcopenia, function and health. Age and Nutrition 8, 4-11.

Chumlea WmC, Zeller C, Siervogel RM \& Guo S (1997b) Reference data for total body water for Caucasian adults, 18 to 64 years of age: The Fels Longitudinal Study. Sixteenth International Congress of Nutrition, Montreal, Book of Abstracts, p. 77.

Cress ME, Schechtman KB, Mulrow CD, Fiatarone MA, Gerety MB \& Buchner DM (1995) Relationship between physical performance and self-perceived physical function. Joumal of the American Geriatrics Society 43, 93-101.

Czajka-Narins DM, Tsui J, Kohrs MD \& Nordstrom JA (1991) Anthropometric indices of a non-institutionalized elderly population. Age and Nutrition 2, 95-103.

Damon A \& Stoudt HW (1963) The functional anthropometry of old men. Human Factors 5, 485-491.

De Groot CPGM, van Staveren WA \& Hautvast JGAJ (1991) EURONUT-SENECA, nutrition and the elderly in Europe. European Journal of Clinical Nutrition 45, Suppl. 3, 1-196.

Deurenberg P, Kusters CSL \& Smit HE (1990) Assessment of body composition by bioelectrical impedance in children and young adults is strongly age-dependent. European Journal of Clinical Nutrition 44, 261-268.

Dutta C, Hadley EC \& Lexel J (1997) Sarcopenia and physical performance in old age: overview. Muscle and Nerve Suppl. 5, S5-S9.

Eveleth PB \& Tanner JM (1976) Worldwide Variation in Human Growth. Cambridge: Cambridge University Press.

Fiatarone MA, Oneill EF, Ryan ND, Clements KM, Solares GR, Nelson ME, Roberts SB, Kehayias JJ, Lipsitz LA \& Evans WJ (1994) Exercise training and nutritional supplementation for physical frailty in very elderly people. New England Journal of Medicine 330, 1769-1775.

Forbes GB (1987) Human Body Composition. New York, NY: Springer-Verlag.

Frontera WR, Hughes VA, Lutz KJ \& Evans WJ (1991) A cross-sectional study of muscle strength and mass in 45- to 78-yr-old men and women. Journal of Applied Physiology 71, 644-650.

Garry PJ (1997) The New Mexico Aging Process Study. Albuquerque, NM: University of New Mexico Press.

Guigoz Y, Vellas BJ \& Garry PJ (1994) The mini nutritional assessment (MNA): a practical assessment tool for grading the nutritional state of elderly patients. Facts and Research in Gerontology 8, Suppl. 2, 15-60.

Guo SS, Harris T \& Studenski S (1997a) Summary of work group I; population-based studies. Muscle and Nerve Suppl. 5, S114-S116.

Guo SS, Wisemandle WA, Tyleshevski FE, Roche AF, Chumlea WC, Siervogel RM, Specker B \& Heubi J (1997b) Inter-machine and inter-method differences in body composition measures from dual energy x-ray absorptiometry and hydrodensitometry. Journal of Nutrition, Health and Aging 1, 29-38.

Guo SS, Zeller C, Chumlea WmC \& Siervogel R (1997c) Agerelated changes in fat and lean tissues from middle-aged to older adults. Journals of Gerontology 37, 253.

Guralnik JM, Branch LG, Cummings SR \& Curb JD (1989) Physical performance measures in aging research. Journals of Gerontology 44, M141-M146.

Guralnik JM \& Kaplan GA (1989) Predictors of healthy aging: Prospective evidence from the Alameda County Study. American Journal of Public Health 79, 703-708.

Guralnik JM, Simonsick EM, Ferrucci L, Glynn RJ, Berkman LF, Blazer DG, Scherr PA \& Wallace RB (1994) A short physical performance battery assessing lower extremity function: Association with self-reported disability and prediction of mortality and nursing home admission. Journals of Gerontology 49 , M85-M94.

Haarbo J, Gotfredsen A, Hassager C \& Christiansen C (1991) Validation of body composition by dual energy X-ray absorptiometry. Clinical Physiology 11, 331-341.

Ham RJ (1991) Indicators of Poor Nutritional Status In Older Americans. Report of Nutrition Screening 1: Toward a Common View. A Consensus Conference. Washington, DC: Nutrition Screening Initiative.

Heymsfield SB, Gallagher D, Visser M, Nunez C \& Wang ZM (1995) Measurement of skeletal muscle: laboratory and epidemiological methods. Journals of Gerontology 50A, 23-29.

Hill (1992)

Johnson J \& Dawson-Hughes B (1991) Precision and stability of dual-energy x-ray absorptiometry measurements. Calcified Tissue International 49, 174-178.

Kaplan GA, Haan MN \& Cohen RD (1992) Risk factors and the study of prevention in the elderly: Methodological issues. In The Epidemiologic Study of the Elderly, pp. 20-36 [RB Wallace and RF Woolson, editors]. Oxford: University Press.

Katz SC, Ford AB, Moskowitz RW, Jack BA \& Jaffe MW (1963) Studies of illness in the aged. The index of ADL: A standardized measure of biological and psychosocial function. Journal of the American Medical Association 185, 914-919.

Kohrt WM (1995) Body composition by DXA: Tried and true? Medicine and Science in Sports and Exercise 27, 1349-1353.

Kuczmarski RJ, Flegal KM, Campbell SM \& Johnson CL (1994) Increasing prevalence of overweight among US adults: The National Health and Nutrition Examination Surveys, 1960-1991. Journal of the American Medical Association 272, 205-211.

Landis RJ, Lepkowski JM, Eklund SA \& Stehouwer SA (1982) A Statistical Methodology for Analyzing Data from a Complex Survey: The First National Health and Nutrition Examination Survey. Data from the National Health Survey. DHHS publication no. (PHS) 82-1366. Vital and Health Statistics series 2, no. 211. Hyattsville, MD: Vital and Health Statistics.

Laskey MA, Flaxman ME, Barber RW, Trafford S, Hayball MP, Lyttle KD, Crisp AJ \& Compston JE (1991) Comparative performance in vitro and in vivo of Lunar DPX and Hologic QDR-1000 dual energy x-ray absorptiometers. British Journal of Radiology 64, 1023-1029.

Lexell J \& Dutta C (1997) Sarcopenia and physical performance in old age. Muscle and Nerve Suppl. 5, S1-S120.

Lexell J, Henriksson-Larsen K, Winblad B \& Sjostrom M (1983) Distribution of different fiber types in human skeletal muscles: Effects of aging studied in whole muscle cross sections. Muscle and Nerve 6, 588-595.

Losonczy KG, Harris TB, Cornoni-Huntley J, Simonsick EM, Wallace RB, Cook NR, Ostfeld AM \& Blazer DG (1995) Does weight loss from middle age to old age explain the inverse weight mortality relation in old age? American Journal of Epidemiology 141, 312-321.

Masters AM, Lasser RP \& Beckman G (1960) Tables of average weight and height of Americans aged 65 to 94 years. Journal of the American Medical Association 201, 658-662.

Nagi SZ (1991) Disability concepts revisited: Implications for prevention. In Disability in America - Toward a National Agenda for Prevention, pp. 309-327 [AM Pope and AR Tarlov, editors]. Washington DC: National Academy Press.

Najjar MF \& Rowland M (1987) Anthropometric Reference Data and Prevalence of Overweight. Vital and Health Statistics, series 11, no. 238. DHEW publication no. (PHS) 87-1688. Rockville, MD: National Center for Health Statistics. 
Pearson MB, Bassey EJ \& Bendall MJ (1985) Muscle strength and anthropometric indices in elderly men and women. Age and Aging 14, 49-54.

Roche AF (1979) Secular trends in human growth, maturation and development. Monographs of the Society for Research and Child Development 44, 120.

Rosenberg IH (1989) Summary comments. American Journal of Clinical Nutrition 50, 1231-1233.

Roubenoff R \& Kehayias JJ (1991) The meaning and measurement of lean body mass. Nutrition Reviews 46, 163-175.

Roubenoff R, Kehayias JJ, Dawson-Hughes B \& Heymsfield SB (1993) Use of dual-energy x-ray absorptiometry in body composition studies: not yet a 'gold standard' American Joumal of Clinical Nutrition 58, 589-591.

Schwartz RS (1997) Sarcopenia and physical performance in old age: introduction. Muscle and Nerve Suppl. 5, S10-S13.

Seeman TE, Guralnik JM, Kaplan GA, Knudsen L \& Cohen R (1989) The health consequences of multiple morbidity in the elderly: The Alameda County Study. Journal of Aging and Health 1, 50-66.

Shephard RJ, Montelpare W, Plyley M, McCracken D \& Goode RC (1991) Handgrip dynamometry, cybex measurements and lean mass as markers of the ageing of muscle function. British Journal of Sports Medicine 25, 204-208.

Steen B, Lundren BK \& Isaksson B (1985) Body composition at age $70,75,79$ and 81 years: A longitudinal population study. In Nutrition, Immunity and Illness in the Elderly, pp. 49-52 [RK Chandra, editor]. New York, NY: Pergamon Press.
Stini WA (1981) Association of early growth patterns with the process of aging. Federation Proceedings 40, 2588-2594.

Vellas B, Chumlea WmC, Béziat F, Ghisolfi-Marque A, Guo S, Conceicao J, Sédeuilh M, Dufetelle R \& Albarede JL (1992) Étude des normes anthropométriques dans une population Francaise de 492 personnes agees en bonne sante et vivant a domicile (A study of the anthropometric norms for a French population of 492 elderly persons in good health living at home) - Anthropometric measures in elderly persons living in Europe. In L'année Gérontologique (The Gerontological Year), pp. 203-217 [J-L Albarede and P Vellas, editors]. Paris: SERDI.

World Health Organization (1995) Physical Status: The Use and Interpretation of Anthropometry. Report of a WHO Expert Committee. Technical Report Series no. 854. Geneva: WHO.

Wolfson L, Judge J, Whipple R \& King M (1995) Strength is a major factor in balance, gait and the occurrence of falls. Journals of Gerontology 50A, 64-67.

Woteki CE, Briefel RR \& Kuczmarski RM (1988) Contributions of the National Center for Health Statistics. American Journal of Clinical Nutrition 47, 320-328.

Young A, Stokes M \& Crowe M (1984) Size and strength of the quadriceps muscles of old and young women. European Journal of Clinical Investigation 14, 282-287.

Zeller C, Guo S, Chumlea WC \& Siervogel R (1997) Age-related changes in total body bone mineral content and bone mineral density: The Fels Longitudinal Study 1929-1996. Journals of Gerontology 37, 13. 